\title{
UZ Cochrane

\section{The prevalence of scoliosis in spina bifida subpopulations: a systematic review}

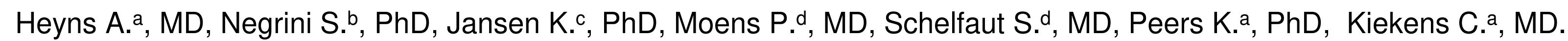 \\ a Physical and Rehabilitation Medicine, University Hospitals Leuven, Belgium \\ ${ }^{b}$ Clinical and Experimental Sciences Department, University of Brescia, Italy \\ c Department of Development and Regeneration, University Hospitals Leuven \\ d Orthopaedic Surgery, University Hospitals Leuven, Belgium
}

\section{Context:}

Prevalence of scoliosis within spina bifida subpopulations is important for screening/diagnosis and treatment purposes.

\section{Objective:}

To determine the prevalence of scoliosis within the spina bifida subpopulations with a systematic review of the literature Data sources:

Medline-Pubmed, Embase, Cochrane and Pedro.

Study selection:

\section{MESH-terms}

Spinal Dysraphism - Neural Tube Defects - Scoliosis

\section{Exclusion criteria}

Articles concerning animal studies, case reports, articles that studied the prevalence of spina bifida in patients with scoliosis, inclusion in the study of patients with scoliosis $\leq 10^{\circ}$ without possibility to identify subgroups with scoliosis $>10^{\circ}$, studies without an own study group or the same patient group as another article, articles that studied neural tube defects besides spina bifida and articles that didn't specify the subpopulations of spina bifida that were investigated.

\section{Data extraction:}

year(s) in which the study was performed, type of study, sample size, criteria for patient selection, subtypes of spina bifida, mean age, sample size, type of radiographs that were used, cut-off value of scoliosis and prevalence of scoliosis.

A $20^{\circ}$ Cobb angle was used as cut-off to create uniform data.

\section{Prevalence of scoliosis in myelomeningocele}

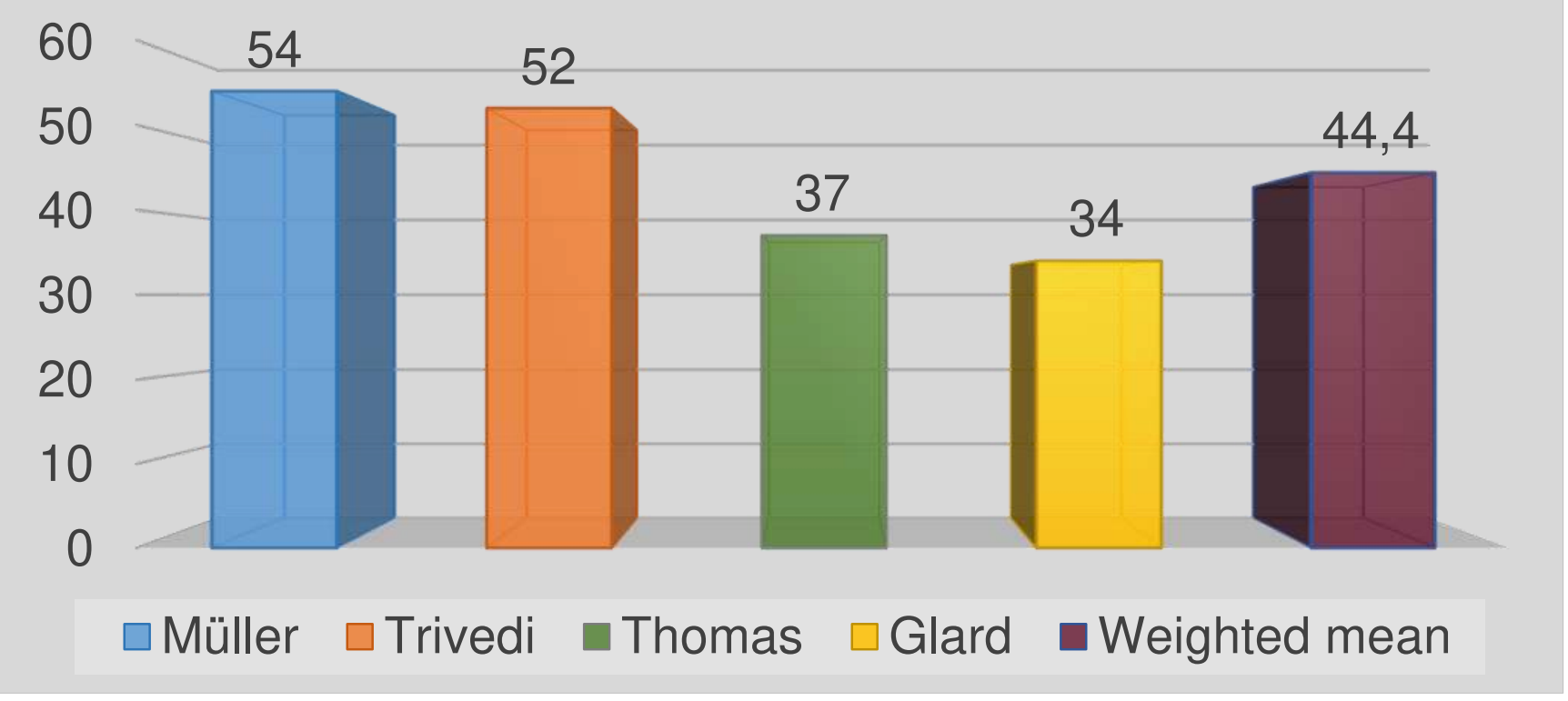

Results:

Two articles concerning diastematomyelia ${ }^{1,2}$ (103 patients: 82 females and 21 males), four about myelomeningocele $e^{3,4,5,6}$ (479 patients: 283 females and 196 males) with an overall weighted prevalence of scoliosis (20 Cobb angle cut off) of $44.4 \%$ and $52.5 \%$ respectively.

\section{Discussion:}

\section{Cut-off value}

Trivedi et al. ${ }^{4}$ proposed, concerning myelomeningocele, a $20^{\circ}$ cutoff as clinically more relevant, since curves $<20^{\circ}$ often resolved, Recommendation: mention results for a $10^{\circ}, 20^{\circ}$ and $30^{\circ}$ cut-off. This way future studies can be used for both epidemiological and clinical research and comparison with idiopathic scoliosis.

\section{Age}

Müller et al. ${ }^{7}$ showed that most progression of scoliosis can be expected before the age of 15 .

Recommendation: use a study population with radiograph at age of 15 years or older.

\section{Radiographic measurements}

Yazici et al. ${ }^{8}$ found a 29,8\% difference in measurement of idiopathic scoliosis in supine and standing position,

Recommendation: mention the percentage of supine/standing/sitting radiographs and create subgroups for each position. These subgroups should be compared to see whether or not there are differences in the prevalence, magnitude and curve location of the scoliotic curve.

\section{Prevalence of scoliosis in diastematomyelia}

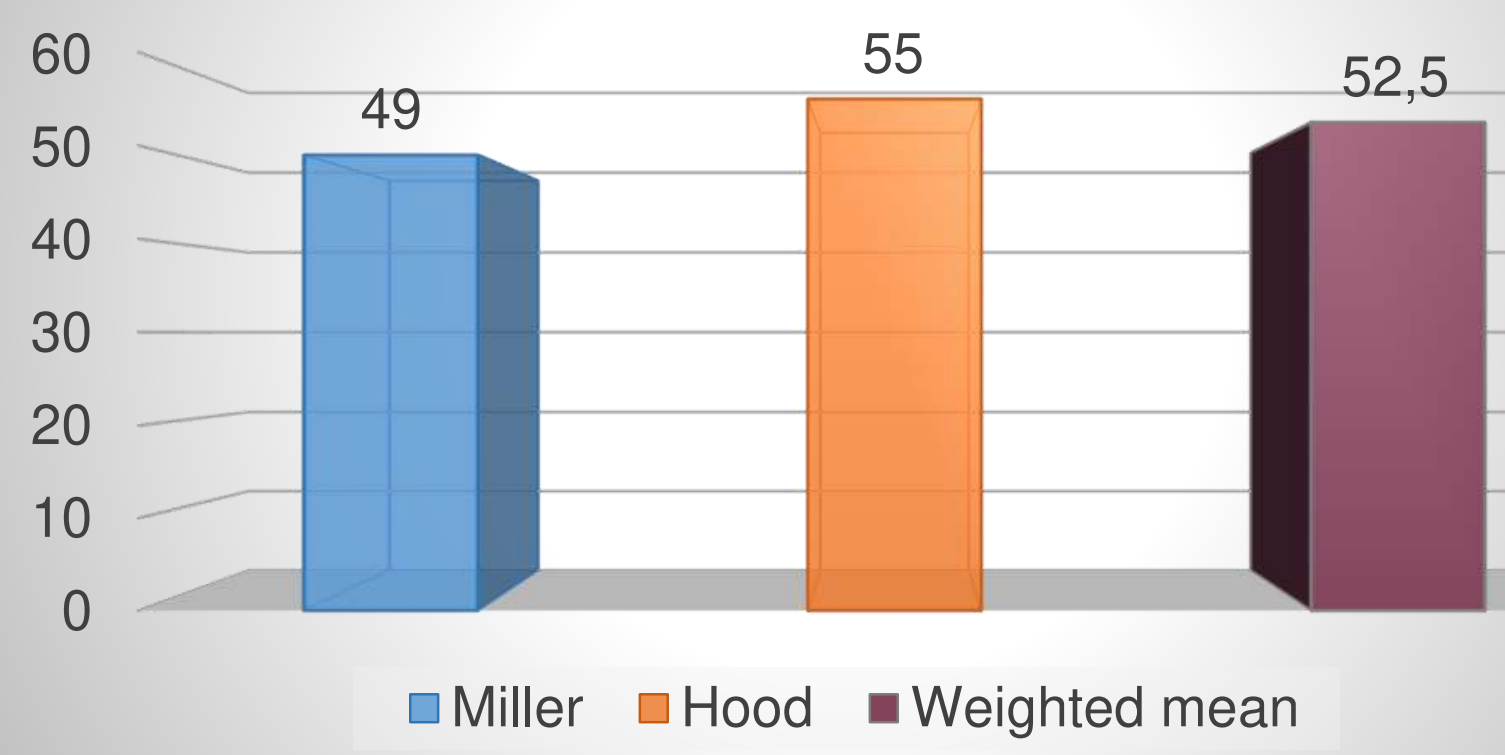

Conclusion: Most studies have a lot of methodological flaws so there is a need for further research with standardisation of data collection to allow comparison of different data.

We recommend to collect the following data to make the data both clinically and epidemiological useful and to allow comparisons between different studies: gender, classification of spina bifida into subpopulations, radiograph at age of 15 years or older or possibility to identify this group, cut off value for scoliosis of $10^{\circ}, 20^{\circ}$ and $30^{\circ}$ Cobb angle, percentage of supine/standing/sitting radiographs with subgroups for each position and ambulatory status.

Miller A, Guille JT, Bowen JR. Evaluation and treatment of diastematomyelia. J Bone Joint Surg Am. 1993;75(9):1308-1317.

Hood RW, Riseborough EJ, Nehme AM, Micheli LJ, Strand RD, Neuhauser EB. Diastematomyelia and structural spinal deformities. J Bone Joint Surg Am. 1980;62(4):520-528.

Müller EB, Nordwall A, E.B. M, Muller EB, Nordwall A. Prevalence of scoliosis in children with myelomeningocele in western Sweden. Spine (Phila Pa 1976). 1992;17(9):1097-1102.

Trivedi J, Thomson JD, Slakey JB, Banta J V, Jones PW. Clinical and radiographic predictors of scoliosis in patients with myelomeningocele. J Bone Joint Surg Am. 2002;84-A(8):1389-1394.

Glard Y, Launay F, Viehweger E, Hamel A, Jouve J-L, Bollini G. Neurological classification in myelomeningocele as a spine deformity predictor. J Pediatr Orthop B. 2007;16(4):287-292.

Hood RW, Riseborough EJ, Nehme AM, Micheli LJ, Strand RD, Neuhauser EB. Diastematomyelia and structural spinal deformities. J Bone Joint Surg Am. 1980;62(4):520-528

Berned Muller E, Nordwall A, Oden A. Progression of scoliosis in children with myelomeningocele. Spine (Phila Pa 1976). 1994

Yazici M, Acaroglu ER, Alanay a, Deviren V, Cila a, Surat a. Measurement of vertebral rotation in standing versus supine position in adolescent idiopathic scoliosis. J Pediatr Orthop. 2001;21(2):252-256. 